\title{
Broadband Truncated Rectangular Microstrip Antenna with E - Shaped Ground Plane
}

\author{
Rajesh Kumar Verma *, P. K. Singhal ** \\ * ( Shri JJT University, Jhunjhunu (Raj.) INDIA \\ ** ( Deptt. Of Electronics \& Comm. Engg.M.I.T.S. ,Gwalior(MP)-INDIA
}

\begin{abstract}
A new design of rectangular microstrip antenna to enhance the bandwidth and reduce the size is presented. The proposed geometry consist of a truncated radiating patch and an $E$ - shaped ground plane. The impedance BW determined is $37 \%$ of the center frequency at $3.86 \mathrm{GHz}$. Size of the proposed geometry is also reduced by $13 \%$ as compared to a conventional patch without any geometry on ground plane.. The microstrip antenna is fed by a coaxial probe to achieve linear polarization. The proposed geometry provides a band of $1420 \mathrm{MHz}(3.15 \mathrm{GHz}$ to $4.57 \mathrm{GHz})$ that is suitable for certain frequencies of $S$ band as well as of $C$ band applications. Also, the proposed geometry provides a peak directivity $7.29 \mathrm{dBi}$, gain $5.84 \mathrm{dBi}$, axial ratio 42.08 $d B$, aperture efficiency $88.56 \%$, radiation efficiency $94.76 \%$ for a band $(3.15 \mathrm{GHz}$ to $4.57 \mathrm{GHz})$. All the simulations are carried out using Zeland IE3D simulation software.
\end{abstract}

Keywords : Broadband, Truncated, Compactness, MSA .

\section{Introduction}

An MSA in its simplest form consists of a radiating patch on one side of a dielectric substrate and a ground plane on the other side as shown in figure 1.1. There are different shapes of the microstrip antenna, such as the square, circular,triangular, semicircular, sectoral, annular ring, but the most common is rectangular. Due to its advantages such as low weight, low profile, low fabrication cost and capability to integrate with microwave integrated circuits technology, the microstrip antennas are well suited for applications such as wireless communication systems, cellular phones, pagers , radar and satellite communication systems[1]-[7]. A major drawback of the MSAs is that they have a narrow bandwidth, typically $1-5 \%$ which is the major limiting factor for the widespread application of these antennas.

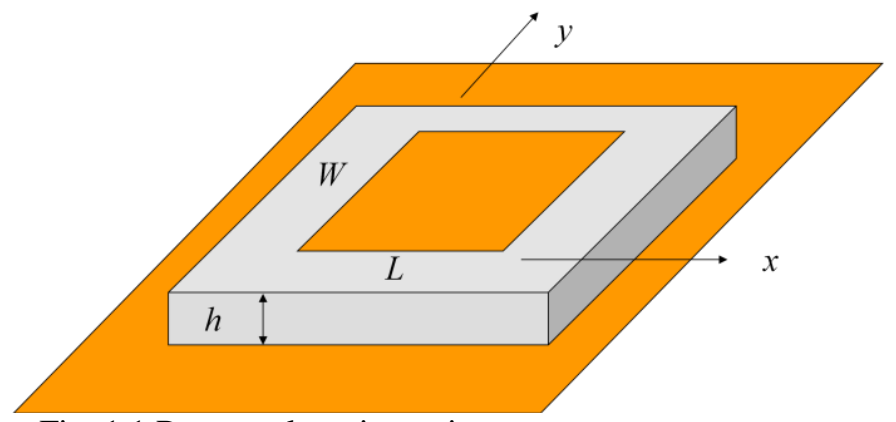

Fig. 1.1 Rectangular microstrip antenna

The BW of the MSAs can be increased by using the modified shape patches, planar multiresonator configurations, multilayer configurations, stacked multiresonator configurations [7,13].

In this paper, a new prototype is presented which consist of a truncated radiating patch and an E-shaped ground plane to enhance the bandwidth.

\section{Proposed Antenna Geometry And Design}

A typical design of rectangular microstrip antenna has been presented here and results are discussed at centre frequency of $2.0 \mathrm{GHz}$. The width and length of the patch are given by [1, 7]:--

$$
\begin{aligned}
& w=\frac{c}{2 f \sqrt{(\varepsilon r+1) / 2}} \\
& \mathrm{~L}=\mathrm{L}_{\text {eff }}-2 \Delta \mathrm{L} \\
& \Delta \mathrm{L}=\frac{0.412 h\left[\varepsilon_{e f f}+0.300\right]\left[\left(\frac{w}{h}\right)+0.264\right]}{\left[\varepsilon_{e f f}-0.285\right]\left[\left(\frac{w}{h}\right)+0.8\right]} \\
& \varepsilon_{\text {eff }}=\left(\varepsilon_{\mathrm{r}}+1\right) / 2+\left[\left(\varepsilon_{\mathrm{r}}-1\right) / 2\right](1+12 \mathrm{~h} / \mathrm{W})^{-1 / 2} \\
& L_{\text {eff }}=\frac{c}{2 f \sqrt{\varepsilon e f f}} \\
& \text { Where, }
\end{aligned}
$$


$\mathrm{C}$ = velocity of light,

$\varepsilon_{\mathrm{r}}=$ dielectric constant of substrate,

$\mathrm{f}$ = operating frequency

$\varepsilon_{\text {eff }}=$ effective dielectric constant,

$\mathrm{L}_{\text {eff }}=$ effective length,

$\Delta \mathrm{L}=$ edge extension

\section{Designing Parameters}

For designing the proposed antenna, the following parameters are used:--

Design frequency

Dielectric constant

$=2.0 \mathrm{GHz}$

$=4.4$

$=0.02$

Loss tangent

Thickness of substrate

$=1.6 \mathrm{~mm}$

Length of the radiating patch $\mathrm{L}=36 \mathrm{~mm}$

Width of the radiating patch $\mathrm{W}=46 \mathrm{~mm}$

Length of the ground plane $\mathrm{Lg} \quad=\quad 46 \mathrm{~mm}$

Width of the ground plane $\mathrm{Wg}=56 \mathrm{~mm}$

Length of the slot Ls $\quad=42 \mathrm{~mm}$

Width of the slot Ws $=4 \mathrm{~mm}$

Truncated corner

$=6 \times 6 \mathrm{~mm}^{2}$

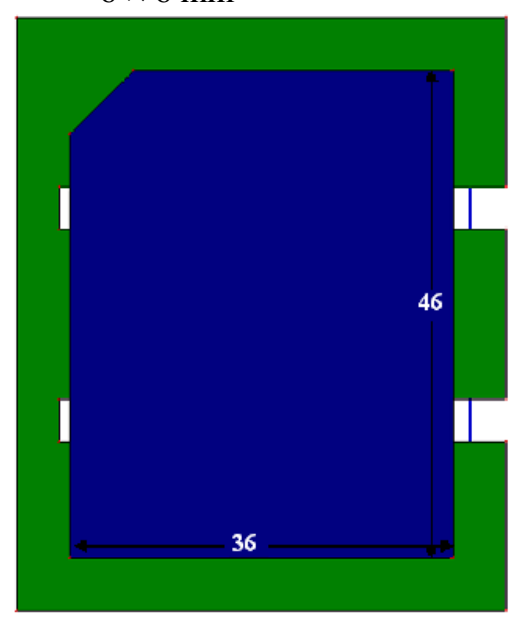

Fig 1.2 Rectangular microstrip antenna with truncated corner.

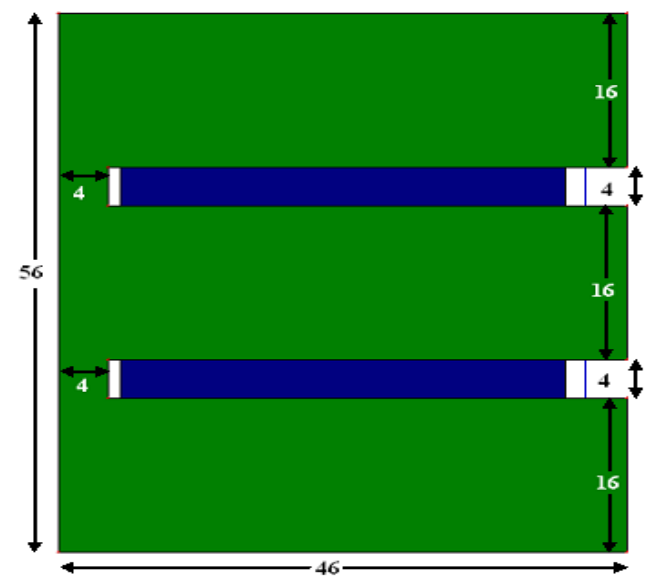

Fig 1.3 E- shaped ground plane of Rectangular microstrip antenna with truncated corner.

\section{Results \& Discussions}

The rectangular microstrip antenna with finite ground plane resonates at different frequencies such as $0.74 \mathrm{GHz}, 1.4 \mathrm{GHz}, 4.0 \mathrm{GHz}$, with maximum impedance $\mathrm{BW}=9.5 \%(3.79 \mathrm{GHz}$ to $4.17 \mathrm{GHz})$ at center frequency $3.98 \mathrm{GHz}$. Now, the ground plane geometry is modified to an $\mathrm{E}-$ shaped ground plane geometry. The new RMSA is simulated which resonates at $1.57 \mathrm{GHz}, 1.94 \mathrm{GHz}, 2.33 \mathrm{GHz}, 3.35 \mathrm{GHz}, 4.12 \mathrm{GHz}, 4.4 \mathrm{GHz}$ with maximum impedance $\mathrm{BW}=30.7 \%(3.10 \mathrm{GHz}$ to $4.21 \mathrm{GHz})$ at center frequency $3.65 \mathrm{GHz}$ and $6.5 \%(4.31$ 
$\mathrm{GHz}$ to $4.60 \mathrm{GHz})$ at center frequency $4.45 \mathrm{GHz}$. Now, a truncated corner $\left(6 \times 6 \mathrm{~mm}^{2}\right)$ is cut in the radiating patch with dimensions $36 \times 46 \mathrm{~mm}^{2}$. The new truncated RMSA with $\mathrm{E}-$ shaped ground plane is simulated and it resonates at $1.59 \mathrm{GHz}, 1.93 \mathrm{GHz}, 3.26 \mathrm{GHz}, 4.08 \mathrm{GHz}, 4.39 \mathrm{GHz}$, with maximum impedance $\mathrm{BW}=36.8 \%$ (3.15 GHz to $4.57 \mathrm{GHz}$ ) at center frequency $3.86 \mathrm{GHz}$. The new impedance BW is approximately 4 times the BW of the RMSA without any geometry on ground plane. Also, the proposed geometry provides a size compactness of $13 \%$, directivity of $7.29 \mathrm{dBi}$ at $4.11 \mathrm{GHz}$, gain of $5.84 \mathrm{dBi}$ at $4.09 \mathrm{GHz}$, axial ratio of $42.08 \mathrm{~dB}$ at $3.15 \mathrm{GHz}$, aperture efficiency $88.56 \%$ at $3.21 \mathrm{GHz}$, and radiation efficiency $94.76 \%$ at $3.15 \mathrm{GHz}$.

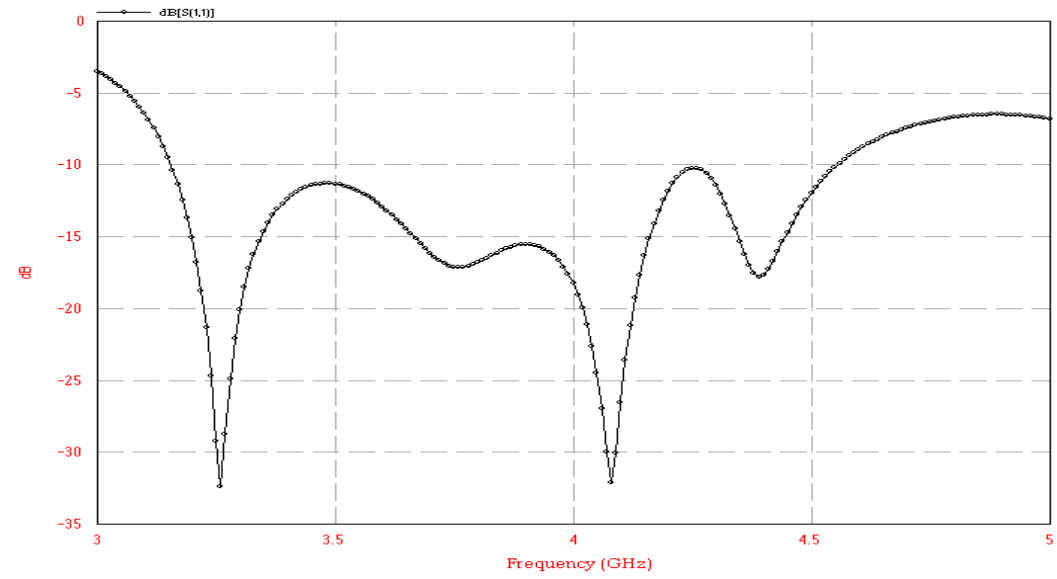

Fig 1.4 Return loss Vs Frequency

Directivity Vs. Frequency

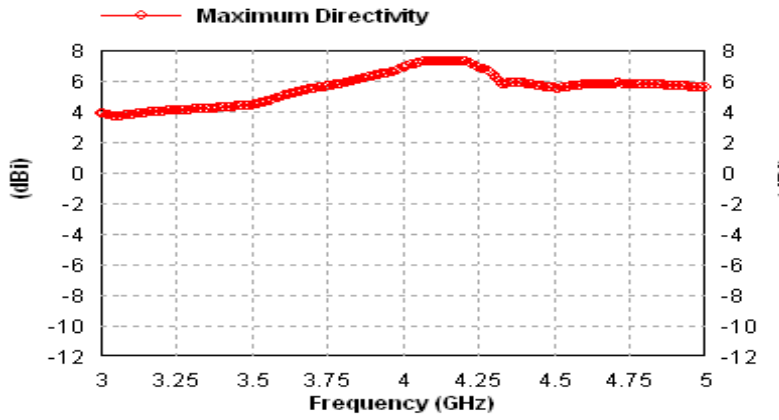

Fig 1.5 Directivity Vs Frequency

Efficiency Vs. Frequency

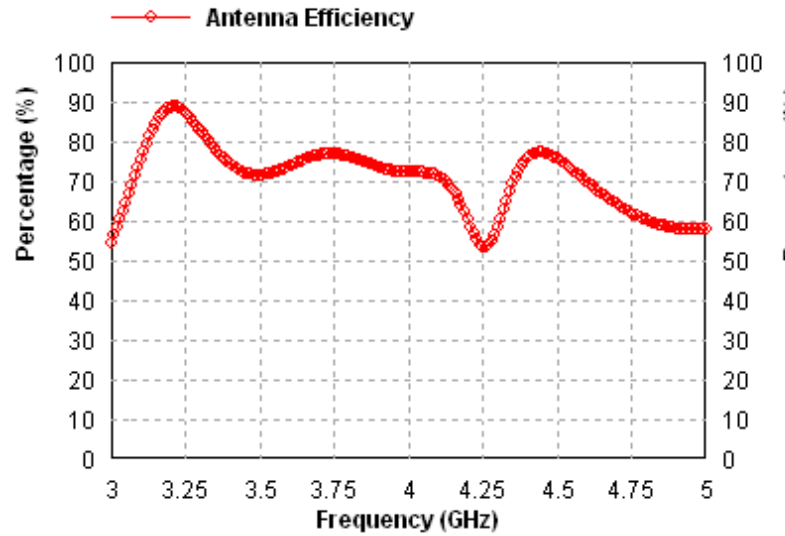

Fig 1.7 Aperture efficiency Vs Frequency
Gain Vs. Frequency

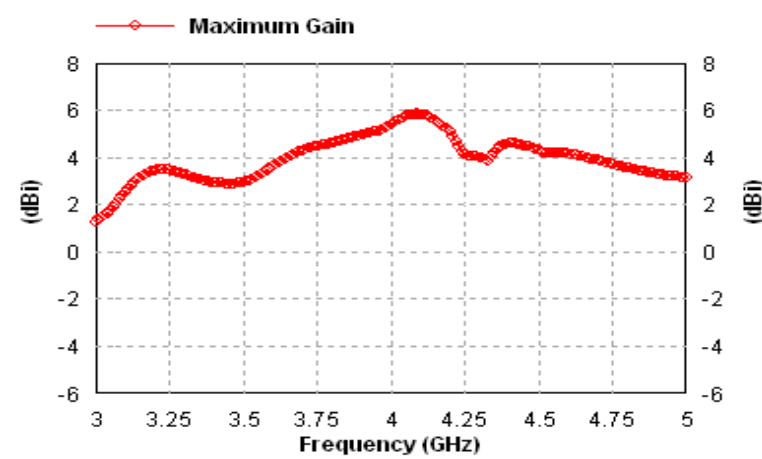

Fig 1.6 Gain Vs Frequency

Efficiency Vs. Frequency

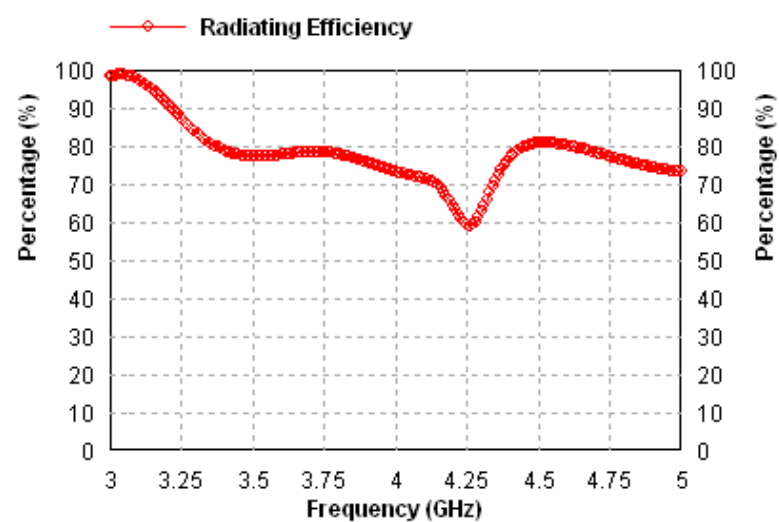

Fig 1.8 Radiating efficiency Vs Frequency 


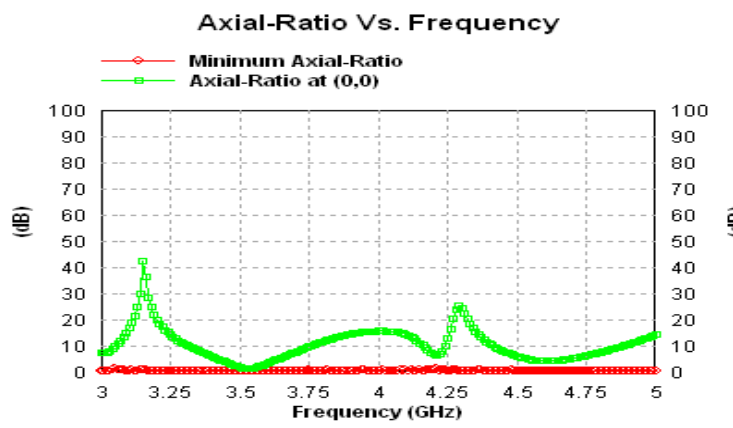

Fig 1.9 Axial Ratio Vs Frequency

\section{Conclusion}

A coaxially fed broadband truncated rectangular microstrip antenna with an $\mathrm{E}$ - shaped ground plane is studied, designed and simulated and compared with a conventional rectangular microstrip antenna without any geometry on ground plane. This configuration provides the impedance bandwidth of $36.8 \%$ with peak directivity $7.29 \mathrm{dBi}$, gain $5.84 \mathrm{dBi}$, axial ratio $42.08 \mathrm{~dB}$, aperture efficiency $88.56 \%$, radiation efficiency 94.76 $\%$ for a band $(3.15 \mathrm{GHz}$ to $4.57 \mathrm{GHz})$ which is suitable for higher frequencies of $\mathrm{S}$ band and lower frequencies of $\mathrm{C}$ band applications.

\section{Acknowledgments}

The author would like to thank Prof. (Dr.) P.K.Singhal, Deptt.of Electronics, M.I.T.S. , Gwalior (MP) for his valuable guidance and also to provide the lab facility in his department.

\section{References}

[1]. Balanis C. A., “Antenna Theory: A Review,” Proc. IEEE, Vol. 80, No. 1, pp. 7-23, January 1992.

[2]. Bahl I. J. and P. Bhartia, Microstrip Antennas, Artech House, Norwood, MA, 1980.

[3[. Collin R. E., Antennas and Radiowave Propagation, McGraw-Hill, New York, 1985.

[4]. James J. R. and P. S. Hall (Eds.), Handbook of Microstrip Antennas, Vols. I and II, Peter Peregrinus, 1989.

[5]. Jordan E. and K. Balmain, Electromagnetic Waves and Radiating Systems, Prentice-Hall,New York, 1968.

[6]. Kraus J. D., Antennas, McGraw-Hill, New York, 1988

[7]. Kumar G. and K. P. Ray,Broadband Microstrip Antennas, Artech House, 2002.

[8]. Sarkar, S., Majumdar, A. D., Mondal, S.,Biswas, S.,Sarkar, D. Sarkar, P. P., "Miniaturization of rectangular microstrip patch antenna using optimized single-slotted ground plane". Microwave and Optical Technology Letters,53,2011: pp.111-115.

[9]. Wong K.L.,C.L. Tang, and J.Y. Chiou , "Broad-Band Probe-Fed Patch Antenna With a W-Shaped Ground Plane", IEEE Transactions On Antennas And Propagation, Vol. 50, No. 6, June 2002.

[10]. Wong K.L and J.Y. Sze, "Slotted rectangular microstrip antenna for bandwidth enhancement," IEEE Trans. Antennas Propag., Vol. 48, No. 8, pp.1148-1152, August, 2000

[11]. Wong K. L. and J. S. Kuo, “A compact microstrip antenna with meandering slots in the ground plane,” Microwave Opt. Technol. Lett. 29, 95-97, April 20, 2001.

[12]. Wong K. L. and T. W. Chiou, "Designs of compact microstrip antennas with a slotted ground plane," IEEE Antennas Propagat. Soc. Int. Symp. Dig. pp. 732-735, 2001

[13]. Wong Kin-Lu-, Compact and Broadband Microstrip Antenas, John Wiley \& Sons,INC. 